\title{
Role of Indian Government in the Development of Organic Agriculture
}

\author{
Archana $\mathrm{K}^{*}$ \\ Assistant professor in Law, KSLU's Law School, Hubli
}

\begin{abstract}
The growth of organic agriculture production and trade has been accompanied by an increase in national legislation in order to set the minimum requirements for organic agriculture and create the institutional framework for certification, thus giving the organic label greater credibility. Government intervention can take the form of public inspection and certification, or the accreditation of private inspection and certification bodies. Legislation also ensures fair competition among producers and facilitates equivalence with other countries for international trade. Because of the health and environmental benefits and trade opportunities associated with organic agriculture, governments may pass regulations that encourage farmers to shift to organic methods, through tax reductions/exemptions, subsidies, or support in research and marketing. In India with the introduction of NPOP programme, minimum standards for organic products have been set up. But the measures taken are not adequate. The paper throws light on the development of different agencies in setting standards for Organic Agriculture.
\end{abstract}

Key Words: Organic Agriculture, IFOAM, APEDA, NPOP and FAO

\section{Introduction:}

India is an Agrarian country with around 60\% of its people directly or indirectly depends upon Agriculture. In ancient times the practice of agriculture is considered to be a greatest service to the society and this practice is inter-twined in their tradition and culture. Agriculture may be defined as an integrated system of techniques to control the growth and harvesting of animal and vegetables. It is an uncomplicated endeavour comprising of technical and practical processes that helps in the maintenance of the ecological balance and protects human resources; and most importantly it is a viable food production system. After the Green revolution and use of chemical fertilisers, people started realising the adverse effects of these chemical fertilizers on earth and started organic agriculture in India.

Organic agriculture is a system for crops, livestock and fish farming that emphasizes environmental protection and the use of natural farming techniques. It is concerned not only with the end-product, but with the entire system used to produce and deliver the agricultural product. To this end, the entire farm cycle, from production and processing, to handling and delivery, excludes the use of artificial products such as genetically modified organisms (GMOs) and certain external agricultural inputs such as pesticides, veterinary drugs, additives and fertilizers. Organic farmers rely instead on natural farming methods and modern scientific ecological knowledge in order to maximize the long-term health and productivity of the ecosystem, enhance the quality of the products and protect the environment.

The growth of organic agriculture production and trade has been accompanied by an increase in national legislation in order to set the minimum requirements for organic agriculture and create the institutional framework for certification, thus giving the organic label greater credibility. Legislations ensure fair competition among producers and facilitate equivalence with other countries for international trade. Because of the health and environmental benefits and trade opportunities associated with organic agriculture, governments sometimes pass regulations that encourage farmers to shift to organic methods, through tax reductions/exemptions, subsidies, or support in research and marketing. This paper focuses on the growth of organic agriculture all over the world and the development of various bodies to set up and maintain standards of organic agriculture. The paper analyses the provisions of NPOP in maintaining the minimum standards.

\section{History of the 'Organic Movement'}

In India, the values of organic agriculture i.e., 'no chemical inputs, crop rotations, environmental preservation' have probably been practiced in traditional forms for centuries. Those methods were largely abandoned, however, during the first half of the 20th century with the advent of engine-powered tractors and synthetic farming chemicals.

But during 1940's itself, some of the farmers realised the potentially harmful effects of such chemicals on food and the environment. Sir Northbourne, an Oxford University agriculturalist, was the first to use the term

* Assistant professor in Law, KSLU's Law School, Hubli, Karnataka, India 
"organic agriculture" in his book, Looking to the Land, which he wrote in response to the industrialisation of agriculture. He criticised industrial agriculture and propounded that, organic methods led to the long term health of soil, production of higher quality goods and a more sustainable form of land use. These ideas gained popularity in Europe and the United States from 1940s. Northbourne and others derived their theories from the principles of biodynamic agriculture, advanced by Rudolf Steiner in 1924. Steiner believed that farmers play an important role in balancing the use of land for agriculture with environmental preservation.

Organic agriculture became visible on a wider scale in the 1960s, when farmers and consumers became concerned that the amount of chemicals used in crop and animal production could have negative consequences for human health and the environment. Since then, it has developed into a more cohesive and organized movement and it is now the fastest growing food sector globally.

Prior to 1980s, the organic agriculture movement was driven by a collection of grassroots organizations, farmers and traders, who formed national associations to advocate for their cause. Many of these associations banded together in 1972 to form the International Federation of Organic Agriculture Movements (IFOAM), an international umbrella organization for the movement. IFOAM today unites over 750 organizations in 108 different countries. The organic movement was especially concerned with the quality of the food and standards that were needed to create consumer trust and to provide assurance that production processes were similar across different farms ${ }^{1}$.

The first legislation to set the standards for organic agriculture appeared in Oregon and California in the United States, in 1974 and 1979 respectively. Consumers created a persistent demand for organic agriculture and beginning in the 1980s, local and national governments responded to it with legislation on organic agriculture. The recognition that organic agriculture could help countries achieve environmental objectives further encouraged governments to adopt agri-environmental laws to promote organic farming ${ }^{2}$.

\section{Importance of Organic agriculture}

From different spheres, Organic agriculture has its own advantages. It can be classified into three subtitles. Namely-

\section{Environmental benefits of organic agriculture}

Land management has a significant impact on the environment. Conventional agriculture prioritizes high yields and does little to harmoniously interact with and preserve its immediate environment. These practices can result in widespread environmental degradation, commonly resulting in soil erosion, water, soil and air pollution, biodiversity loss, and desertification. They also contribute to global warming. In India, agriculture today accounts for more than thirteen percent of global anthropogenic greenhouse gas emissions. ${ }^{3}$

Conversely, organic agriculture uses an individualized approach to land management that emphasizes preservation of a land's natural ecosystem, while consuming less energy and reducing the risks of pollution common to conventional agriculture. Organic agriculture, therefore, seeks to offer a responsible alternative to conventional practices in the face of ever growing concerns over climate change and environmental degradation. Soil erosion is a main cause of loss of yield capacity and fertility. Long term comparisons between conventional and organic farms have found that organic methods improve the fertility and overall health of the soil. Organically managed soils also demonstrate better moisture-retention capacity than those of conventional farms, which is important in arid climates and to reduce the risk of desertification.

Soil conservation is therefore one of the key concepts in organic agriculture. Soil fertility is actually a cornerstone of organic farming by necessity because farmers cannot use synthetic products to restore degraded lands. They rely instead on maintaining and building soil fertility through multi-cropping systems, crop rotations, organic fertilizers, and minimum tillage. Organic farming has the ability to increase organic content in the soil, enhancing its capacity to retain water and circulate pollutants. Organic methods also counter soil erosion because they use natural pesticides and maintain a permanent soil cover, restoring even degraded soils quickly. Although there is little scientific evidence demonstrating that organic agriculture can reverse desertification, there are several practical examples of organic agriculture systems returning degraded lands back to fertility. This suggests that organic farming may prove to be an effective means to counter desertification.

Water pollution in agriculture is also due to soil erosion and nitrate and synthetic products leaking into water supplies. In light of the fact that organic farms do not use synthetic products, the risk of water pollution is greatly diminished. Organically-tended soils also show reduced rates of nitrate pollution in the water supply, as

\footnotetext{
${ }^{1}$ Willer H and Youssefi M., 2007. The world of organic agriculture: statistics and emerging trends. IFOAM.

${ }^{2}$ Heckman J. A history of organic farming -transitions from the USDA war in the soil to the USDA National Organic Program, In Wise traditions in food, farming and the healing arts (Winter 2006).

${ }^{3}$ Intergovernmental Panel on Climate Change, Fourth Assessment Report (2007) available at: www.ipcc.ch.
} 
organic farms use fewer nitrates than conventional farms, and organic soils have an increased capacity to retain that Organic farms also aim at consuming less energy and being more energy efficient than conventional farms.

The environmental benefits of organic agriculture can also extend to climate change. The International Panel on Climate Change has strongly advocated the adoption of sustainable cropping systems such as those used on organic farms to reduce carbon emissions. Organic methods are indeed expected to result in lower emissions; carbon emissions are between forty-eight to sixty-six percent lower than on conventional farms. This is due to the high levels of organic matter found in organic soils, which allow the soil to trap and convert carbon, lowering emissions over time. Organic farms also tend to reduce nitrous dioxide emissions, simply because they use less nitrogen than conventional farms. This is particularly significant in light of the fact that agriculture today is responsible for sixty-five to eighty percent of nitrous dioxide pollution, which contributes to the depletion of the ozone layer.

Organic agriculture is beneficial to nature protection and biodiversity conservation. The use of synthetic products and emphasis on mono-crop specialization and intensive yields that characterizes conventional agriculture has led to a considerable reduction in the number and variety of animals and plants used in agriculture. The International Union for Conservation of Nature's (IUCN) Red List of threatened species noted that habitat loss is the main threat to biodiversity, and that agriculture affected seventy percent of all threatened bird species and forty-nine percent of all plant species. Organic farmers, on the other hand, rely on biodiversity for their success. Organic farmers depend on wildlife for pollination, pest control and maintenance of soil fertility. The absence of synthetic pesticides provides an improved natural habitat for birds, insects and micro-organisms in the soil. As a result of such practices, studies show that bird densities, plant populations, earthworms and insect populations are much higher on organic farms than elsewhere.

Finally, animal health and welfare is another key issue in organic agriculture. Generally speaking, organic agriculture relies on disease preventive measures while restricting the administration of veterinary drugs to livestock. Organic livestock standards further require that animals receive adequate space, fresh air and suitable shelter. They also require specific nutritional programs using primarily organic feeds. This is a more humane and natural approach to livestock farming, which conventional agriculture does not necessarily take into consideration. There are also possible health benefits to this approach, as these techniques reduce stress in animals which is thought to prevent diseases.

\section{Social benefits of organic agriculture}

Organic agriculture may have a significant social impact on rural communities. To begin with, organic farming may lead to improved employment opportunities in local communities. Organic farming often requires more manual labour to compensate for the loss of synthetic fertilizers and pesticides, and thus generates more jobs in rural communities. The amount of extra labour required varies based on the product and farm in question. In general, however, the labour needed to manage an organic farm is ten to twenty percent higher than on comparable conventional farms. Organic farmers also diversify their crops and spread their planting schedules throughout the year in order to maintain biodiversity and enhance the health of the soil. This creates opportunities for year-round employment, reduces turnover and may alleviate problems related to migrant labour. Crop diversification also mitigates the effects of crop failure by spreading the risk among a wider variety of crops and products. Greater job opportunities on organic farms contribute to strengthening rural communities as well, by halting exodus to urban areas for jobs.

Organic farming has the effect of strengthening local communities and supporting rural development. In order to remain competitive, farmers must adapt to local conditions by managing labour, land and resources in a way that maximizes production and remains sensitive to the environment. Doing so requires constantly experimenting with new techniques and pooling local knowledge to learn best practices. Farmers also rely on their neighbours to maintain certain standards in order to ensure the integrity of their own air, water and soil. Collaboration on these issues strengthens ties within the community, which leads to partnerships and greater organization among organic farmers. Organized groups or cooperatives can thus pool their resources, enjoy greater access to markets, and gain leverage in trade negotiations. There is some evidence that increased cooperation results in more active participation in local government and new businesses among rural communities.

Many organic farms also incorporate fair trade principles with respect to labour welfare. Through the implementation of labour rights related to organic agricultural practices, organic producers agree upon minimum social and labour standards. To that end, farmers contribute to providing labourers with liveable wages, safe and healthy working conditions and access to social services. The organic movement believes that these social requirements are important, but recognizes that specific standards can be controversial and difficult to implement across numerous countries.

Consumer protection is another cornerstone of organic agriculture. Consumers prefer organic products to those made on conventional farms because they know that organic products avoid synthetic pesticides and fertilizers, are good for the environment, and are perceived to produce foods that are healthier and taste better. 
Strong regulatory frameworks, whereby the government verifies organic certifications, are necessary for consumers to trust the products they purchase.

Finally, organic agriculture can contribute to food security. Although the global food supply is adequate, 850 million people still go hungry. In addition, the cost of food has risen dramatically in the past decade and there is less genetic diversity in our foods due to conventional agricultural methods. Consequently, large populations are increasingly exposed to the risk of food shortage due to disease and poverty. Organic agriculture may have the potential to meet these challenges. Considering the fact that organic methods do not require expensive chemical inputs, organic production is considered a more accessible means for rural farmers to become self-sufficient. Organic agriculture also improves access to food by reducing risks of disease, increasing biodiversity and productivity over the long term, and providing a means for local production and access to food. Advocates for conventional farming argue that organic farming decreases yields.

\section{Economic benefits of organic agriculture}

Organic agriculture has seen tremendous economic growth in the last decade. This has been mainly demand-driven, as consumers have become increasingly concerned with the safety of conventionally-grown foods and the ethical downfalls of industrial agriculture. Farmers, in turn, have realized that consumers are willing to pay a premium for organically grown foods. This is particularly attractive to farmers in developing nations, as it is expected to provide access to lucrative and emerging markets. Income constraints currently limit consumer demand mainly to the industrialized world: organic products are generally priced higher than their conventional counterparts both to cover the higher cost of production and processing and to capture unseen savings linked to issues such as environmental protection, animal welfare, and rural development. Governments have also contributed to this growth, by subsidising conversions to organic farming, as they have recognized that organic farming can help them achieve environmental, food security, and rural development goals.

Organic methods can be used to produce foods and plants as well as non-traditional agricultural products. This includes non-wood forest products (NWFP), such as nuts, mushrooms, fruits, herbs, bush meat and plant and animal products used for medicinal or cosmetic purposes. The use of organic methods in woodlands and forests also promotes environmentally-friendly uses of natural resources. Organic methods are also used for fish from fish farms and honey from apiculture farms. These are both nascent markets, which have found willing consumers in developed countries. Consumers buy organic products because they expect a certain standard of production that is environmentally-friendly and free of any artificial inputs.

Organic certification ensures those standards are met and is essential for consumer-trust and expansion of the organic market. Organic consumers are attuned to the type of certification a product receives in order to assess what quality of product they purchase. Organic certification also ensures inspection and compliance, harmonizes standards across different countries and facilitates sales agreements. Certification bodies ascertain that the products meet the standards that are set by either private or public institutions. As will be seen, these standards are created either by in-country legislation or by entities at the international level.

\section{International Guidance on Organic Agriculture}

Several attempts were made to set up standards for organic agricultural products, all over the world. As a result some guidelines were also issued to the member countries to get accredited to organic status. These guidelines are as follows:

\section{Codex Alimen Tarius Guidelines}

Heightened consumer interest in food quality and safety as well as increased concern about the potential for food standards to be applied as trade barriers led to the establishment of the Codex Alimentarius Commission (Codex) by a resolution of the governing bodies of the Food and Agriculture Organization of the United Nations (FAO) in 1961 and the World Health Organization (WHO) in 1963. Primary objectives of this commission are to protect consumer health and to ensure fair practices in food trade through the elaboration, harmonization and publication of food standards and other related texts. Codex brings together scientists, technical experts, government regulators and international consumer and industry organizations to develop food standards. Codex operates based on its Procedural Manual, which includes the Codex Statutes, the Rules of Procedure and the Procedures for the Elaboration of Codex Standards and Related Texts, as well as guidelines and other provisions applicable by Codex subsidiary bodies which should be read in conjunction with the Procedures The Codex Alimentarius Commission meets in principle every year, alternately in Rome and in Geneva,. Membership is open to all members of FAO or WHO, and currently includes 184 countries and one regional economic integration organization (the European Union) $)^{4}$.

\footnotetext{
${ }^{4}$ FAO. 2005, Perspectives and guidelines on food legislation, with a new model food law, Legislative Study 87 (2005) 
The Executive Committee acts on behalf of the Codex Commission between its sessions, generally meeting once before each Commission session and convening other sessions if required. More than forty years after its creation, the Codex Alimentarius (Latin for food code) has become the authoritative collection of internationally adopted food standards and related texts covering foods traded internationally, whether processed, semi-processed or raw. The Codex Alimentarius includes many maximum residue limits established for pesticides and veterinary drugs in foods and animal feeds, acceptable levels of food additives and maximum levels for contaminants. The preparation of draft food standards and related texts, whether they be intended for worldwide use, for a given region, takes place in Codex committees. Membership in these committees is open to all Codex members, and international organizations may attend, as observers, committee sessions that are of interest to them. Generally, committees are financially maintained and hosted by member states.

Codex Commodity Committees develop standards that apply to aspects of specific foods or classes of food. Such standards generally concern quality factors such as the composition or presentation of certain products. The Codex Commodity Committee subject matters range from fresh fruits and vegetables to processed fish and fishery products. General subject Committees focus on so-called "horizontal" subjects - such as food hygiene, labelling, additives and contaminants. These committees develop concepts and principles applicable to foods in general (or applicable to specific foods or food groups) review provisions in Codex commodity standards as required Committees addressing food safety issues often rely on expert advice, consulting internationally recognized experts in special subject areas and seeking guidance from independent FAO/WHO expert committees or consultations.

\section{International Federation of Organic Agriculture Movements (IFOAM)}

The International Federation of Organic Agriculture Movements (IFOAM), established in 1972 and located in Bonn, Germany, is the international nongovernmental organization providing an umbrella for all organic agriculture organizations. Currently uniting around 700 member organizations in more than 100 countries, its goal is the worldwide adoption of ecologically, socially and economically sound systems based on the principles of organic agriculture. Through international conferences, meetings and other fora, IFOAM facilitates an ongoing dialogue about the status and future of organic agriculture.

IFOAM has developed and maintains the Organic Guarantee System, which seeks to provide a common system of standards, verification and market identity for the organic world. IFOAM also implements specific projects that facilitate the adoption of organic agriculture methods, particularly in developing countries, and represents the organic agriculture movement at the United Nations and other intergovernmental agencies.

\section{FAO ${ }^{5}$ 's involvement with organic agriculture}

FAO's interest in organic agriculture stems from its potential to contribute to the goal of greater food security and rural development. At the 2007 International Conference on Organic Agriculture and Food Security in Rome, FAO member countries noted organic agriculture's ability to increase access to food in rural communities, create a more stable food supply, and sustain natural resources. FAO has been involved in organic agriculture since the late 1990s, when the Committee on Agriculture recommended that an inter-disciplinary program be developed on the topic. Organic agriculture was officially included onto FAO's agenda as a means to promote sustainable development in March 1999. These first FAO activities were mainly concerned with disseminating information on organic agriculture to allow actors; legislators, producers, consumers to make informed decisions. To that end, the FAO website ${ }^{6}$ was launched in 2000 and is regularly updated with publications and information on organic agriculture. FAO has also tried to harmonize standards and requirements for organic agriculture through partnerships with IFAOM and the United Nations Conference on Trade and Development ("UNCTAD"). To that end, the International Taskforce on Harmonization and Equivalence in Organic Agriculture, compromising representatives from ministries of agriculture and trade as well as actors in the field, was established in 2002 to facilitate international trade ${ }^{7}$. FAO's involvement in organic agriculture has also included providing assistance to member countries, upon their request in establishing legislative and regulatory frameworks provide information on accessing markets and agricultural expertise on improving quality and performance of organic farms ${ }^{8}$.

\footnotetext{
${ }^{5}$ The Food and Agriculture Organization of the United Nations

${ }^{6}$ www.fao.org.

7 International Federation of Organic Agriculture Movement, 'Basic Standards for Organic Production and Processing' (version 2005), available at: www.ifoam.org. .

${ }^{8}$ CTA/FAO /ITC. 2001. World markets for organic fruit and vegetables. Opportunities for developing countries in the production and export of organic horticultural products.
} 


\section{Legal Framework on organic agriculture in India}

To have consonance with these international standards, India had to take steps to identify organic products. As a result in 1985 Agricultural and Processed Food Products Export Development Authority Act has been passed. Along with that, two authorities are also been established to regulate the organic agriculture field. Namely-

\section{The Agricultural and Processed Food Products Export Development Authority (APEDA)}

APEDA was established under the Agricultural and Processed Food Products Export Development Authority Act, passed by the Indian Parliament in December 1985. Pursuant to said Act, its main functions include: promoting the export oriented production and development of scheduled products (including fruits, vegetables, meat, dairy, cereal, cacao products and non-basmati rice); fixing of standards and specifications for the scheduled products for the purpose of exports; carrying out inspection of meat and meat products for quality purposes; and other matters. These are three out of the five Statutory Boards under the Ministry of Commerce and Industry (the other two being on rubber and tobacco).

Only products certified by accredited bodies as conforming to national organic standards may be marketed as organic in India. In a similar vein, agricultural products are only allowed to be exported as organic if certified by an accredited agency as conforming to NPOP standards. As will be seen in the subsequent sections, the Indian organic programme was modelled after the IFOAM Basic Standards for Organic Production and Processing, the Codex Alimentarius Guidelines and the EU Regulation 2092/91. It should be noted that India is among the few developing countries to have been included into the list of third countries with organic equivalency pursuant to Article 11(1) of EU Regulation 2092/91 until 30 June 2009. In addition to the export advantages to the EU market, such inclusion opens the door for recognition of equivalency by other countries included in the EU list. In fact, as of 1 January 2007 until 30 June 2009, Indian organic rules and control system have also been recognised as equivalent by Switzerland.

\section{National Programme on Organic Production (NPOP)}

In 2000, the Ministry of Commerce and Industry of India launched the National Programme on Organic Production (NPOP) ${ }^{9}$. The NSCOP is composed of members from the Ministry of Commerce and Industry, the Ministry of Agriculture, the Agricultural and Processed Food Products Export Development Authority (APEDA), the Coffee, Spices and Tea Boards, and other government and private organizations associated with the organic movement. Since its launch in 2001, the Indian organic programme has been periodically reviewed by the NSCOP, with the latest revisions incorporated in May 2005. The NPOP has following objectives ${ }^{10}$ and principles:

a) To provide the means of evaluation of certification programmes for organic agriculture and products as per approved criteria;

b) To accredit certification programmes;

c) To facilitate certification of organic products in conformity to the National Standards for Organic Products; and

d) To encourage the development of organic farming and organic processing.

General principles of organic agriculture are found in Section 3 of the NPOP, preceding the specific requirements for the production, handling and processing of organic products. In this regard, the NPOP follows closely the structure of the IFOAM Basic Standards, where 'general principles', 'recommendations', 'basic standards' and 'derogations' are established for individual aspects of organic production, handling and processing. However, this does not necessarily indicate that the substantive content of the NPOP is identical to IFOAM Basic Standards.

\section{Organic Labelling and Claims}

Section 3.5 of the NPOP lays down the general principles, recommendations and specific requirements for the use of organic labelling and claims. As a matter of principle, it is stated that labelling shall convey clear and accurate information on the organic status of the products. Following closely the IFOAM Basic Standards, four categories of products are distinguished for labelling purposes on the basis of their organic composition:

- Single-ingredient products 100 percent organic: raw or processed agricultural products containing 100 percent certified organic ingredients (excluding water and salt, but including additives) may be labelled "produce of organic agriculture" or similar description.

\footnotetext{
${ }^{9}$ Ministry of Commerce and Industry, 'National Programme for Organic Production', available at: www.apeda.gov.in. ${ }^{10}$ Section 2
} 
- Multi-ingredient products with at least 95 percent organic ingredients: raw or processed agricultural products containing a minimum of 95 percent certified organic ingredients (by raw material weight, excluding water and salt, but including additives) may be labelled "certified organic" or a similar description.

- Multi-ingredient products with at least 70 percent organic ingredients: raw or processed agricultural products containing between 70 percent and 95 percent certified organic ingredients (by raw material weight, excluding water and salt, but including additives) may be labelled "made with organic ingredients" or a similar description on the principal display, provided that the proportion of organic ingredients is clearly indicated. Such products cannot be simply labelled "organic".

- Multi-ingredient products with less than 70 percent organic ingredients: raw and processed agricultural products containing less than 70 percent certified organic ingredients may only contain indications that an ingredient is organic on the ingredient list, but cannot be labelled "organic".

In all cases, the person or company legally responsible for the production and processing of an organic product shall be identifiable and no such product can be labelled as GE (genetic engineering) or GM (genetic modification) free in order to avoid potentially misleading claims about the end product. In addition, all raw materials of multi-ingredient products, including additives, must be listed on the product label in order of their weight percentage (NPOP, sec. 3.5).

The use of the "Indian Organic" logo is regulated in Section 6 of the NPOP. This logo may only be attached to products that have been duly certified by accredited inspection and certification agencies as satisfying all organic standards prescribed in the NPOP (NPOP, sec. 6.1). Whereas the use of certifiers' mark is voluntary, it is mandatory to place the "Indian Organic" logo on all certified organic products originating from India. Lastly, as in the IFOAM Basic Standards (II.B.7.1.2), a possibility is provided for the labelling of products that are in-conversion to organic production, followed by a requirement that it be clearly distinguishable from the label for organic products.

\section{Production of livestock and livestock products}

As to conversion periods, livestock products can be sold as organic only after the farm has been under active organic management for at least twelve months. The NPOP does not however establish the exact length of conversion periods applicable to different animal species, which instead is determined by the competent certification body. Only in the case of dairy and egg products is this period set at a minimum of thirty days. Whatever the length of the conversion period for other animal species, it shall only begin once the production unit has been placed under the established inspection system and organic production methods must be utilised throughout this period. The NPOP generally encourages the whole farm, including livestock, to be converted to organic production. Nonetheless, partial conversion is allowed insofar as organic and conventional parts of the farm are clearly separate and not switched back and forth.

In terms of livestock sources or origin, the NPOP generally encourages the choice of breeds that are naturally adapted to local conditions, in order to promote the health and wellbeing of the animals. In addition, livestock should be, as a matter of principle, born and raised on holdings that conform to national organic standards. Nonetheless, when organic livestock is not available, the accredited certification body may authorise conventional animals to be brought into the farm, subject to specified conditions regarding age and quantity. This possibility is also contemplated in the Codex Alimentarius Guidelines and IFOAM Basic Standards.

Concerning nutrition, livestock should be, as a matter of principle, provided with 100 percent organically grown feedstuffs of good quality, with the prevailing part coming from the farm itself or produced in cooperation with other organic farms within the region. Where this proves impossible, the NPOP establishes maximum percentages of feed that can be sourced from conventional farms for each animal category. The competent certification body may nonetheless grant time-limited derogations from these percentages in cases of unforeseen severe natural or man-made events, extreme climatic conditions and in areas where organic agriculture is in early stages of development. In addition, products that are prohibited as feed additives or supplements are listed in the main text of the NPOP. Finally, conditions for the use of vitamins, minerals and fodder preservative from unnatural sources shall be defined by the competent certification agency.

Subsection 3.3.7 of the NPOP deals with the health care of organic livestock. While a general emphasis is placed on management practices that encourage animals' resistance, the NPOP provisions are largely limited to the administration of veterinary medicinal products, departing from the Codex Alimentarius Guidelines. Natural medicines and methods, including homeopathic and ayurvedic products, are generally preferred to conventional veterinary medicines, recourse to which shall only be had when no other alternative is available. Vaccination of organic livestock is generally permitted when required by national law, or if the accredited certification body deems it necessary in response to a particular disease or/and within a particular region. However, genetically engineered vaccines are prohibited in all circumstances. 


\section{Accreditation and Certification}

Section 4 of NPOP lays down the criteria and procedure that are applicable to the accreditation of inspection and certification agencies, together with minimum measures to be implemented during the inspection and certification of organic producers, processors and handlers. The NSCOP also functions as the National Accreditation Body (NAB), which is responsible for approving and supervising private agencies in charge of organic inspection and certification (NPOP, sec. 4). It should be noted that establishment of an accreditation and certification system constitutes the most extensive part of the NPOP, but only its main elements will be addressed in the following text. Accreditation is open to any individual, firm, co-operative or society that has been engaged in the inspection and certification of organic production and/ or processing operations for a minimum period of one year. Applications shall be made to APEDA, must be accompanied by the applicable accreditation fee and must contain, inter alia, documentary evidence of the applicants' ability to comply with the established criteria.

Further, the remainder of Section 4 of the NPOP prescribes minimum standards for developing inspection and certification programmes. Organic inspection and certification shall apply to the whole production and processing chain. Each step in the handling of an organic product must be inspected at least once per year.

\section{Conclusion}

To conclude, the paper focused on the legal aspects of organic agriculture that will capture and summarise the practical lessons organic agriculture legislation. It is not an easy task to draft national legislation to govern and maintain minimum standards in organic agriculture. NPOP is a first step in unravelling the complex and highly technical issues related to drafting national legislation on organic agriculture, but the programme i self is not clear. From the view point of India, encouragement for organic agriculture by means of subsidies, etc by the government is much needed. Besides that, knowledge of the adverse effect of chemical based agriculture and awareness as to the socio- economic benefits of organic agriculture is the need of the day in India. 